\title{
Adjuvant vaginal cuff brachytherapy for high-risk, early stage endometrial cancer
}

\author{
Harriet Belding Eldredge-Hindy, MD', Gary Eastwick, BS', Pramila Rani Anne, MD', Norman G. Rosenblum, MD, PhD², \\ Russell J. Schilder, MD³, Raffi Chalian, MD², Allison M. Zibelli, MD³, Christine H. Kim, MD², Robert Den, MDl
}

'Department of Radiation Oncology, Kimmel Cancer Center, Thomas Jefferson University Hospital, ${ }^{2}$ Department of Obstetrics and Gynecology, Division of Gynecologic Oncology, Thomas Jefferson University Hospital, ${ }^{3}$ Department of Medical Oncology. Kimmel Cancer Center, Thomas Jefferson University Hospital, Philadelphia, USA

\begin{abstract}
Purpose: To report outcomes following adjuvant high-dose-rate vaginal brachytherapy (VBT) with or without chemotherapy for high-intermediate risk (HIR) and high-risk, early stage endometrial cancer as defined in Gynecologic Oncology Group trial 0249.

Material and methods: From May 2000 to January 2014, 68 women with HIR and high-risk endometrial cancer underwent surgical staging followed by VBT. Median VBT dose was 21 Gy delivered in three fractions prescribed to $0.5 \mathrm{~cm}$ depth. Paclitaxel $175 \mathrm{mg} / \mathrm{m}^{2}$ and carboplatin area under the curve 6 was administered every 21 days in sequence with VBT. Actuarial survival estimates were calculated using the Kaplan-Meier method.

Results: Patient demographics included a median age of 66 years (range: 36-91) and stages IA (49\%), IB (38\%), and II (13\%), respectively. Thirty-one (46\%) patients had HIR disease with endometrioid histology, and 33 (48\%) patients had serous or clear cell histology. Thirty-seven (54\%) patients received a median 3 cycles (range: 3-6) of chemotherapy in addition to VBT, and 65 patients (96\%) completed all prescribed therapy. During a median follow up of 33.1 months (range: 4.0-161.7), four patients have recurred, including one vaginal recurrence. The 3-year estimates of vaginal, pelvic, and distant recurrences were $1.9 \%, 2.4 \%$, and 9.1\%, respectively. The 3-year rates of disease-free and overall survival were $87.7 \%$ and $93.9 \%$, respectively.

Conclusions: Early outcomes with adjuvant VBT with or without chemotherapy demonstrate high rates of vaginal and pelvic control for women with HIR disease. Early vaginal and pelvic relapses in high-risk patients suggest that pelvic external beam radiotherapy is warranted in this subgroup, but additional data from large phase III trials is warranted.
\end{abstract}

J Contemp Brachytherapy 2014; 6, 3: 262-270 DOI: $10.5114 /$ jcb.2014.45031

Key words: clear cell carcinoma, endometrial cancer, high-dose-rate brachytherapy, high-intermediate risk, papillary serous.

\section{Purpose}

There is significant controversy surrounding adjuvant radiation therapy for early-stage endometrial cancer. Four large randomized trials have demonstrated a reduction in pelvic recurrences with the addition of pelvic external beam radiotherapy (EBRT) following standard surgical therapy [1-4]. However, this improvement in local control owed to EBRT is not without commensurate toxicity and does not improve survival [1-7].

In three of the randomized control trials, patient subgroups were identified in whom an important benefit in local control was derived from adjuvant radiotherapy $[1,2,4]$. For example, in Gynecologic Oncology Group
(GOG) 99, the high-intermediate risk (HIR) subgroup was formulated based on previously identified high-risk features (i.e. high grade tumors, advanced age, lymphovascular invasion (LVI), and deep myometrial invasion). This HIR subgroup was found to not only compose twothirds of those patients who recurred, but also derived the largest benefit in local control from the addition of pelvic EBRT. At four years, the risk of recurrence or death in the HIR subgroup decreased from $36 \%$ to $17 \%$ with the addition of pelvic EBRT - a $53 \%$ reduction in relative risk. In women with low-risk disease, the benefits of pelvic EBRT were less clinically significant [1]. There is significant prognostic heterogeneity among women with early stage endometrial cancer and, accordingly, there is strong 
evidence for the routine use of adjuvant radiation therapy in well-defined HIR and high-risk patient subgroups.

A widely recognized benefit of radiotherapy is its ability to reduce recurrences at the vaginal cuff, the most common site of local failure [1-4,8]. With this notion, the second Post-operative Radiation Therapy in Endometrial Cancer (PORTEC) trial further refined the role of adjuvant radiotherapy. The results of this trial showed that vaginal brachytherapy (VBT) was non-inferior in providing vaginal local control compared to pelvic EBRT in women with features similar to the HIR group defined in GOG 99 [1,9]. Despite the adequate local control and reduced toxicity observed with VBT, relapses were common and disease-free survival (DFS) approached only $82 \%$ at five years, suggesting a need for new strategies to improve outcomes [9].

Despite the plethora of data from randomized trials, unanswered questions still remain. Of particular interest is defining the role of chemotherapy in early stage disease, with early data already emerging [10-12]. Furthermore, appropriate adjuvant therapies for early-stage carcinomas with high-risk, papillary serous or clear cell histology are not well established as this subgroup has not been consistently included in randomized trials for endometrial cancer $[1,9]$. Collective experience suggests stage I and II serous, and clear cell carcinomas carry similar recurrence rates as HIR disease [13-27]. Thus, contemporary clinical trials in endometrial cancer are challenged to define the optimal adjuvant therapy for patients with HIR and high-risk, early stage disease [14,28,29]. GOG 0249 is a trial in which HIR and high-risk patients were randomized following surgical staging to adjuvant pelvic EBRT alone (control arm) or VBT with three cycles of chemotherapy (experimental arm) [14,30]. The objective of this trial is to determine if the combination of chemotherapy and VBT can increase DFS when compared to pelvic EBRT and final results have not been reported.

Clinical practice in North America has migrated towards the use of VBT without EBRT for early-stage disease [31]. Our institutional preference is to deliver VBT with or without chemotherapy as an adjuvant strategy in patients with early stage, HIR and high-risk disease. Given this evolution in practice, the purpose of this study is to review the outcome of patients with HIR and high-risk disease, as defined in the contemporary trial GOG 0249 [14], to determine if acceptable rates of local control and DFS have been achieved at our institution without the use of pelvic EBRT.

\section{Material and methods}

Following approval by the Institutional Review Board, an institutional database was queried to identify patients with endometrial cancer who were treated with VBT between May 1, 2000 and January 5, 2014 and met criteria for International Federation of Gynecology and Obstetrics (FIGO) 2009 stage I and II disease. Sixty-eight women who met GOG 0249 criteria for HIR and highrisk disease were included $[14,30]$. The patient cohort includes: (1) FIGO stage I endometrioid adenocarcinomas with HIR disease as defined in GOG 99 with or without positive peritoneal cytology, and two subgroups of pa- tients with high-risk, early stage disease. High-risk, early stage disease includes: (a) stage II endometrial carcinoma with cervical stromal invasion, and (b) FIGO stage I-II patients with type II, high-risk histology (clear cell or serous) and negative peritoneal cytology. Patients with non-epithelial uterine malignancies were excluded.

All women underwent surgical staging, which consisted of a hysterectomy, bilateral salpingo-oophorectomy, and peritoneal washings. Pelvic lymphadenectomies with or without para-aortic lymph node dissection were performed according to physician discretion. In women who had serous or clear cell histology, an omental biopsy and para-aortic lymph node sampling was performed. Patient demographics and tumor characteristics were obtained using electronic medical records and pathology reports. Pathologic stage in the present series has been designated according to FIGO 2009.

Patient cases were routinely reviewed in a multi-disciplinary conference in order to establish treatment recommendations for adjuvant therapy. Chemotherapy was recommended for patients with: (1) serous or clear cell carcinoma, or (2) grade 3 tumors with deep (greater than $50 \%)$ myometrial invasion or LVI. Adjuvant chemotherapy was carboplatin and paclitaxel administered every three weeks with initial dosing of area under the curve 6 and $175 \mathrm{mg} / \mathrm{m}^{2}$, respectively. Beginning in 2011, our institution adopted a policy of administering chemotherapy prior to VBT so; chemotherapy typically began 3-6 weeks following surgery. In scenarios where VBT was administered first, chemotherapy began within three weeks of completion of VBT. Toxicity due to adjuvant therapy was assessed and scored every three weeks according to the National Cancer Institute's Common Terminology Criteria for Adverse Events version 4.0.

VBT was administered with high-dose-rate (HDR) brachytherapy using Iridium-192 and a remote afterloader system. All patients underwent a pelvic exam prior to applicator insertion to ensure adequate healing of the vaginal apex after surgery [32]. While in the dorsal lithotomy position, a single-channel vaginal cylinder with the maximum tolerated diameter was inserted into the vagina. Pretreatment planning and dosimetry was performed prior to the first treatment, including routine use of three-dimensional treatment planning which began in 2008. Image-guidance with orthogonal images or cone beam computed tomography was performed prior to each fraction delivery as a quality assurance measure in order to confirm applicator position and size. The treatment length included one-half to two-thirds of the vaginal length from the apex extending distally toward the meatus, with a minimum treatment length of $4 \mathrm{~cm}$. There are several acceptable fractionation regimens for VBT and, as a result, prescription dose varied and was most commonly: (1) 7 Gy $\times 3$ fractions prescribed at a depth of $0.5 \mathrm{~cm}$ from the cylinder surface, or (2) $6 \mathrm{~Gy} \times 5$ fractions prescribed to the vaginal surface. The later fractionation was favored in young or sexually active patients. Patients were treated on non-consecutive weekdays over a twoweek treatment course and chemotherapy was not administered on days that brachytherapy was delivered. 
Routine surveillance after completion of adjuvant therapy included history and physical exam every 3-6 months for two years and then every 6 months thereafter. Vaginal cytology and imaging were performed annually or as clinically indicated.

The Kaplan-Meier method was used to determine rates of actuarial survival. DFS and overall survival (OS) were calculated based on time from surgery until progression or death. Patients alive without progression were censored at the date of last clinical follow-up for endometrial cancer. Vaginal relapses occurred in the vagina; pelvic relapses included intra-pelvic recurrences outside of the vagina, and distant relapses occurred outside of the pelvis or retroperitoneum. DFS was defined as time to first relapse in any location with events including recurrence or death. Log-rank test was used for univariate analysis. Due to small number of disease recurrences and deaths, a multivariate analysis was not possible.

Table 1. Patient and tumor characteristics

\begin{tabular}{|c|c|c|c|}
\hline Characteristic & $\begin{array}{l}\text { All patients } \\
n=68(\%)\end{array}$ & $\begin{array}{c}\text { VBT }+ \text { chemotherapy } \\
n=37(\%)\end{array}$ & $\begin{array}{l}\text { VBT alone } \\
n=31(\%)\end{array}$ \\
\hline Median age (range) & $66(36-91)$ & $65(36-83)$ & $70(51-91)$ \\
\hline \multicolumn{4}{|l|}{ Race } \\
\hline White & $52(76)$ & $28(76)$ & $24(77)$ \\
\hline Black & $16(24)$ & $9(24)$ & $7(23)$ \\
\hline \multicolumn{4}{|l|}{ Stage } \\
\hline IA & $33(49)$ & $22(59)$ & $11(35)$ \\
\hline IB & $26(38)$ & $11(30)$ & $15(48)$ \\
\hline II (occult) & $9(13)$ & $4(11)$ & $5(16)$ \\
\hline High-intermediate risk [1] & $31(46)$ & $6(16)$ & $25(81)$ \\
\hline High risk & $37(54)$ & $31(84)$ & $6(19)$ \\
\hline \multicolumn{4}{|l|}{ Histology } \\
\hline Endometrioid & $30(44)$ & $4(11)$ & $26(84)$ \\
\hline Adenocarcinoma, NOS & $3(4)$ & $2(5)$ & $1(3)$ \\
\hline Papillary serous & $24(35)$ & $23(62)$ & $1(3)$ \\
\hline Clear cell & $6(9)$ & $5(14)$ & $1(3)$ \\
\hline Mixed serous and clear & $3(4)$ & $2(5)$ & $1(3)$ \\
\hline Adenosquamous & $2(3)$ & $1(3)$ & $1(3)$ \\
\hline Grade 1 & $6(9)$ & $1(3)$ & $5(16)$ \\
\hline Grade 2 & $17(25)$ & $1(3)$ & $16(52)$ \\
\hline Grade 3 & $45(66)$ & $35(94)$ & $10(32)$ \\
\hline$<50 \%$ myometrial invasion & $33(49)$ & $25(68)$ & $8(26)$ \\
\hline$\geq 50 \%$ myometrial invasion & $35(51)$ & $12(32)$ & $23(74)$ \\
\hline \multicolumn{4}{|l|}{ Tumor size (cm) } \\
\hline Median & 3.5 & 3.1 & 4 \\
\hline Range & $0.6-10$ & $0.6-6$ & $1.2-10$ \\
\hline LVI present & $21(31)$ & $9(24)$ & $12(39)$ \\
\hline LVI absent & $47(69)$ & $28(76)$ & $19(61)$ \\
\hline Peritoneal cytology positive & $3(4)$ & $2(5)$ & $1(3)$ \\
\hline Peritoneal cytology negative & $65(96)$ & $35(95)$ & $30(97)$ \\
\hline \multicolumn{4}{|l|}{ Lymph node } \\
\hline Sampling & $13(19)$ & $5(14)$ & $8(26)$ \\
\hline Dissection & $47(69)$ & $29(78)$ & $18(58)$ \\
\hline None & $8(12)$ & $3(8)$ & $5(16)$ \\
\hline \multicolumn{4}{|l|}{ Number of nodes dissected } \\
\hline Median (range) & $20(4-49)$ & $18(4-38)$ & $20(6-49)$ \\
\hline
\end{tabular}

VBT - vaginal brachytherapy, NOS - not otherwise specified, LVI - lymph-vascular invasion 


\section{Results}

\section{Patient and tumor characteristics}

Sixty-eight women with HIR and high-risk endometrial cancer received adjuvant VBT without pelvic EBRT and were included in this study. Baseline patient and tumor characteristics are illustrated in Table 1. The median age was 66 years and all but one patient were post-menopausal. The FIGO 2009 stage was IA in $33(49 \%)$, IB in $26(38 \%)$, and occult II in $9(13 \%)$ patients. Approximately half of patients $(n=31)$ met criteria for HIR endometrial adenocarcinoma, as defined in GOG trial 99 [1]. Additionally, approximately half of patients $(n=33)$ had aggressive histologic subtypes including serous, clear cell carcinoma, and carcinoma with mixed serous and clear cell features. Approximately one-third $(n=21)$ of patients had LVI, but positive peritoneal cytology was not common $(4 \%)$. Fifty-nine (87\%) patients underwent total abdominal hysterectomy and bilateral salpingo-oophorectomy, while nine patients (13\%) underwent laparoscopic-assisted vaginal hysterectomy and bilateral salpingo-oophorectomy. Sixty patients $(88 \%)$ had staging of the pelvic lymph nodes with a median of 20 nodes examined, while para-aortic lymph node staging was performed in 45 (66\%).

Thirty-seven (54\%) of patients received both adjuvant chemotherapy and VBT. Thirty-one (46\%) patients received adjuvant VBT alone including: four patients who refused chemotherapy, eight patients with medical contraindications to chemotherapy, and 19 patients for whom chemotherapy was not recommended. The characteristics of these patient subgroups are also described in Table 1. In short, the majority of patients who received both chemotherapy and VBT had papillary serous or clear cell histology. In contrast, the women who received VBT alone, commonly had HIR endometrioid adenocarcinomas.

\section{Treatment compliance and toxicity}

Sixty-five of the 68 patients $(96 \%)$ completed the planned course of adjuvant therapy. Thirty-seven (54\%) patients received a median of 3 cycles (range: 3-6) of chemotherapy in sequential fashion with VBT. Twenty patients received chemotherapy prior to $\mathrm{VBT}$ and 14 patients received VBT prior to chemotherapy. Three patients with papillary serous carcinoma and deep myometrial inva- sion received therapy in a "sandwich" fashion - six cycles of chemotherapy with VBT given between the third and fourth cycle.

Chemotherapy was carboplatin and paclitaxel in all but two patients: one patient received paclitaxel alone and a second patient received carboplatin and docetaxel due to pre-existing peripheral neuropathy. Two patients required a dose reduction of the taxane due to grade 2 peripheral neuropathy that limited instrumental activities of daily living. One patient required dose reduction of carboplatin due to grade 3 neutropenia and immune system toxicity. Thirty four patients (92\%) were able to complete all cycles of prescribed chemotherapy. Acute chemotherapy-related toxicities are illustrated in Table 2 and are largely characterized by mild, grade 1-2 peripheral neuropathy, hematologic and gastrointestinal toxicities. There were no grade 4 or 5 toxicities observed. There were two grade 3 toxicities including community acquired pneumonia in an immune-compromised patient and one episode of symptomatic anemia requiring transfusion.

All 68 patients were able to complete VBT. The most common fractionation schemes used during VBT were: $21 \mathrm{~Gy}$ in three fractions prescribed to $0.5 \mathrm{~cm}$ depth $(n=42)$, $30 \mathrm{~Gy}$ in five fractions prescribed to cylinder surface $(n=14)$, or other fractionation $(n=12)$. The median cylinder diameter and treatment length were $3.0 \mathrm{~cm}$ (range: 2.5-4.0) and $4.8 \mathrm{~cm}$ (range: $4-9 \mathrm{~cm}$ ), respectively. The reported acute toxicities occurring during VBT were all mild and are illustrated in Table 2. Furthermore, after a median follow-up of 33.1 months (range: 4.0-161.7), late toxicities continue to be mild and include only grade 1 vaginal stenosis $(n=13)$ and grade 2 vaginal stenosis $(n=1)$. Twenty-six patients were compliant with use of a vaginal dilator. Nine patients reported that they were able to remain sexually active following VBT.

\section{Patient outcomes}

After a median follow up of 33.1 months, four patients developed relapsed disease, two of which occurred in patients who had not received adjuvant chemotherapy. The overall 3-year estimates of vaginal, pelvic, and distant recurrences are $1.9 \%, 2.4 \%$, and $9.1 \%$, respectively. One high-risk patient with stage II, grade 2 , endometrioid carci-

Table 2. Reported acute toxicities during adjuvant therapy

\begin{tabular}{|c|c|c|c|c|c|c|c|c|c|c|c|}
\hline \multirow{2}{*}{$\begin{array}{l}\text { Adverse effect } \\
\text { Grade } \\
\end{array}$} & \multicolumn{5}{|c|}{$\begin{array}{l}\text { During chemotherapy } \\
\qquad(n=37)\end{array}$} & \multirow{2}{*}{$\begin{array}{l}\text { Adverse effect } \\
\text { Grade }\end{array}$} & \multicolumn{5}{|c|}{$\begin{array}{l}\text { During vaginal brachytherapy } \\
\qquad(n=68)\end{array}$} \\
\hline & 1 & 2 & 3 & 4 & 5 & & 1 & 2 & 3 & 4 & 5 \\
\hline Fatigue & 7 & - & - & - & - & Fatigue & 8 & - & - & - & - \\
\hline Peripheral neuropathy & 3 & 15 & - & - & - & Vaginal & 13 & 1 & - & - & - \\
\hline Gastrointestinal & 8 & 10 & - & - & - & Gastrointestinal & 5 & 1 & - & - & - \\
\hline Neutropenia & 4 & 3 & 1 & - & - & Genitourinary & 4 & 1 & - & - & - \\
\hline Non-neutropenia hematologic & 3 & 1 & 1 & - & - & & & & & & \\
\hline Myalgias & 3 & 1 & - & - & - & & & & & & \\
\hline Pruritis & 1 & 2 & - & - & - & & & & & & \\
\hline
\end{tabular}


noma and deep myometrial invasion developed an isolated vaginal apex recurrence 15 months after VBT. This recurrence was successfully salvaged with pelvic EBRT and repeat VBT, but the patient later developed pulmonary metastases. A second high-risk patient with stage IA papillary serous carcinoma developed a recurrent mass in the true pelvis with associated abdomino-peritoneal carcinomatosis two years after adjuvant chemotherapy and VBT and has died due to disease. A third patient had a grade 3 , endometrioid carcinoma with LVI and $>50 \%$ myometrial invasion was treated with VBT alone and developed metastatic disease in thoracic spine and orbit four months after surgery and has died due to disease. Finally, a fourth patient with grade 3, endometrioid carcinoma, and $>50 \%$ myometrial invasion (HIR disease) was treated with VBT and chemotherapy, and developed an isolated intra-thoracic recurrence and is alive with disease.

At the time of analysis, four deaths have occurred including two that were due to endometrial cancer. Threeyear site-specific recurrence rates and survival rates are presented in Tables 3 and 4. Distant recurrences occurred more frequently than loco-regional recurrences. The 3-year rates of DFS and OS are $87.7 \%$ and $93.9 \%$, respectively. Outcomes were assessed for the HIR and high-risk subgroups. In patients with HIR disease, there were no recurrences in the vagina or pelvis. In patients with high-risk disease (cervical stromal invasion or type II histology), 3-year estimates of vaginal and pelvic relapse were $3.2 \%$ and $3.8 \%$, respectively (Table 4). Univariate analysis (Table 5) demonstrated age younger than 65 years to be associated with improved DFS at three years $(p=0.02)$.

\section{Discussion}

The findings of this study indicate that adjuvant VBT without pelvic EBRT is well tolerated and could be a sufficient radiation strategy in women with HIR and high-risk endometrial cancer. At three years, the rates of vaginal recurrence, pelvic recurrence, DFS, and OS were $1.9 \%, 2.4 \%$, $87.7 \%$, and $93.9 \%$, respectively. These outcomes occurred in the setting of excellent treatment compliance, mostly mild, grade 1-2 acute toxicity and minimal vulvo-vaginal late toxicity, to date. To the authors knowledge, this is the only series to examine outcomes following VBT in HIR and high-risk patients defined in the contemporary trial GOG 0249 [14].

Traditionally, standard adjuvant therapy for women with high-risk endometrial cancer has included pelvic EBRT [1-7]. In the past decade, there has been a perceptible change in clinical practice favoring the use of VBT alone without EBRT. In fact, a recent analysis of the Surveillance Epidemiology and End Results registry detected an increase in use of VBT from $52.9 \%$ to $59.3 \%$ in women with HIR disease as defined by GOG 99 following publication of the trial in 2004. Growth in VBT usage occurred with a simultaneous decrease in use of EBRT [31]. This shift in clinical practice likely stems from the

Table 3. Estimated 3-year rate of relapse and survival following vaginal brachytherapy with or without chemotherapy

\begin{tabular}{lccccc} 
Endpoint & $\begin{array}{c}\text { Number } \\
\text { events }\end{array}$ & \multicolumn{4}{c}{ Estimated 3-year rate } \\
\cline { 3 - 7 } & & $\begin{array}{c}\text { All patients } \\
(n=68)\end{array}$ & $\begin{array}{c}\text { VBT }+ \text { chemotherapy } \\
(n=37) \\
\text { Percent }(95 \% \mathrm{Cl})\end{array}$ & $\begin{array}{c}\text { VBT alone } \\
(n=31)\end{array}$ & $p$ value \\
Percent $(95 \% \mathrm{Cl})$ & 0 & $4.5(0.6-28.1)$ & 0.24 \\
\hline Vaginal failure & 1 & $1.9(0.2-12.9)$ & $4.0(0.6-25.2)$ & 0 & 0.39 \\
\hline Pelvic failure & 1 & $2.4(0.4-15.8 \%)$ & $7.9(2.1-28.0)$ & $10.1(2.4-37.6)$ & 0.79 \\
\hline Distant metastasis & 4 & $9.1(3.6-23.2)$ & $88.5(68.4-96.2)$ & $86.9(63.8-95.7)$ & 0.64 \\
\hline Disease free survival & 6 & $87.7(74.4-94.3)$ & $96.2(75.7-99.5)$ & $90.8(67.4-97.7)$ & 0.81
\end{tabular}

Table 4. Estimated 3-year rate of relapse and survival among patients with high-risk and high-intermediate risk endometrial cancer

\begin{tabular}{|c|c|c|c|c|c|}
\hline \multirow[t]{2}{*}{ Endpoint } & \multirow{2}{*}{$\begin{array}{l}\text { Number } \\
\text { events }\end{array}$} & \multicolumn{4}{|c|}{ Estimated 3-year rate } \\
\hline & & $\begin{array}{l}\text { All patients } \\
\quad(n=68) \\
\text { Percent }(95 \% \mathrm{Cl})\end{array}$ & $\begin{array}{c}\text { High risk } \\
(n=37) \\
\text { Percent }(95 \% \mathrm{Cl})\end{array}$ & $\begin{array}{l}\text { High-intermediate risk [1] } \\
(n=31) \\
\text { Percent }(95 \% \mathrm{Cl})\end{array}$ & $p$ value \\
\hline Vaginal failure & 1 & $1.9(0.2-12.9)$ & $3.2(0.4-20.8)$ & 0 & 0.41 \\
\hline Pelvic failure & 1 & $2.4(0.4-15.8 \%)$ & $3.8(0.5-24.3)$ & 0 & 0.43 \\
\hline Distant metastases & 4 & $9.1(3.6-23.2)$ & $8.9(2.3-31.6)$ & $8.9(2.2-32.7)$ & 0.67 \\
\hline Disease free survival & 6 & $87.7(74.4-94.3)$ & $89.5(70.7-96.5)$ & $85.4(60.1-95.2)$ & 0.63 \\
\hline Overall survival & 4 & 93.9 (82.1-98) & $96.4(77.2-99.5)$ & $90.4(66-97.6)$ & 0.68 \\
\hline
\end{tabular}

tIncludes stage /I with cervical stromal invasion or stage I-II with clear cell or serous carcinoma. 
findings that VBT offers DFS in HIR patients that is comparable to pelvic EBRT, with no compromise in OS, and diminished treatment-related toxicities [9,33]. PORTEC-2 played an integral role in establishing a role for adjuvant VBT alone and, currently, VBT may be considered as an adjuvant monotherapy in the majority of women with surgically-staged stage I endometrial cancer [34].
A substantial portion of the literature reporting outcomes following VBT without EBRT include women with low-intermediate or intermediate-risk endometrial cancer. As such, there is more controversy surrounding the use of VBT without pelvic EBRT in women with highrisk endometrial cancer. For example, National Comprehensive Cancer Network (NCCN) Clinical Practice

Table 5. Univariate analysis for disease-free and overall survival

\begin{tabular}{|c|c|c|c|c|}
\hline Characteristic & 3-year DFS (\%) & $p$ value & 3-year OS (\%) & $p$ value \\
\hline Age $<65$ & 100 & \multirow{2}{*}{0.02} & 100 & \multirow{2}{*}{0.08} \\
\hline Age $\geq 65$ & 78 & & 89 & \\
\hline FIGO stage I & 90 & \multirow{2}{*}{0.27} & 95 & \multirow{2}{*}{0.80} \\
\hline FIGO stage II & 78 & & 89 & \\
\hline High-intermediate risk & 85 & \multirow{2}{*}{0.63} & 90 & \multirow{2}{*}{0.68} \\
\hline High risk & 90 & & 96 & \\
\hline Type I histology & 79 & \multirow{2}{*}{0.07} & 83 & \multirow{2}{*}{0.15} \\
\hline Type II histology & 96 & & 100 & \\
\hline Grade 1 or 2 & 86 & \multirow{2}{*}{0.82} & 92 & \multirow{2}{*}{0.76} \\
\hline Grade 3 & 88 & & 95 & \\
\hline$<50 \%$ myometrial invasion & 91 & \multirow{2}{*}{0.32} & 96 & \multirow{2}{*}{0.93} \\
\hline$\geq 50 \%$ myometrial invasion & 83 & & 92 & \\
\hline LVI present & 83 & \multirow{2}{*}{0.49} & 82 & \multirow{2}{*}{0.11} \\
\hline LVI absent & 89 & & 97 & \\
\hline Chemotherapy & 89 & \multirow{2}{*}{0.64} & 96 & \multirow{2}{*}{0.81} \\
\hline No chemotherapy & 87 & & 91 & \\
\hline
\end{tabular}

DFS - disease free survival, OS - overall survival, FIGO - International Federation of Gynecology and Obstetrics, LVI - lymph-vascular invasion Type I-endometrioid, adenocarcinoma not otherwise specified, adenosquamous, Type II - papillary serous or clear cell carcinoma

Table 6. Reported outcomes of select series investigating vaginal brachytherapy without pelvic external beam radiotherapy for high-intermediate and high-risk, early stage endometrial cancer

\begin{tabular}{|c|c|c|c|c|c|c|c|c|c|c|}
\hline Author & $n$ & Population & $\begin{array}{l}\text { Surgically } \\
\text { staged }\end{array}$ & $\begin{array}{l}\text { Percent } \\
\text { receiving } \\
\text { chemo }^{\ddagger}\end{array}$ & $\begin{array}{l}\text { Time } \\
\text { point } \\
\text { (years) }\end{array}$ & $\begin{array}{l}\text { Vaginal } \\
\text { failure } \\
(\%)\end{array}$ & $\begin{array}{l}\text { Pelvic } \\
\text { failure } \\
(\%)\end{array}$ & $\begin{array}{l}\mathrm{DM} \\
(\%)\end{array}$ & $\begin{array}{l}\text { DFS } \\
(\%)\end{array}$ & $\begin{array}{l}\text { OS } \\
(\%)\end{array}$ \\
\hline Nout RA [9] & 213 & $\mathrm{HIR}^{\dagger}$ & No & 0 & 5 & 1.8 & 3.8 & 8.3 & 82.7 & 84.8 \\
\hline Atahan IL [35] & 128 & $\begin{array}{l}\text { Intermediate- to } \\
\text { high-risk stage }{ }^{\dagger}\end{array}$ & Yes & 0 & 5 & 1.6 & - & 3.1 & 93.0 & 96.0 \\
\hline McCloskey SA [36] & 77 & HIR & No & 0 & 4 & 1.2 & 3.4 & 4.6 & - & - \\
\hline $\begin{array}{l}\text { Eldredge-Hindy } \\
\text { [Present series] }\end{array}$ & 68 & $\begin{array}{l}\text { HIR, stage II, stage } \\
\text { I-II UPSC and CC }\end{array}$ & Yes & 54 & 3 & 1.9 & 2.4 & 9.1 & 87.7 & 93.9 \\
\hline Barney BM [20] & 103 & $\begin{array}{c}\text { Stage I UPSC } \\
\text { and CC }\end{array}$ & Yes & 34 & 5 & 3.0 & 7.0 & 10.0 & 88.0 & 84.0 \\
\hline Townamchai K [25] & 37 & $\begin{array}{c}\text { Stage I-II UPSC } \\
\text { and CC }\end{array}$ & Yes & 75 & 2 & 3.2 & 6.5 & - & 89.3 & 100 \\
\hline Desai N [37] & 77 & $\begin{array}{c}\text { Stage I-II UPSC } \\
\text { and CC }\end{array}$ & Yes & 79 & 5 & 2.7 & 5.8 & 6.6 & 88.0 & 91.0 \\
\hline Kiess AP [24] & 41 & $\begin{array}{c}\text { Stage I-II UPSC } \\
\text { and CC }\end{array}$ & Yes & 100 & 5 & 0 & 9.0 & 10.0 & 85.0 & 90.0 \\
\hline
\end{tabular}

$N$-number, chemo - chemotherapy, DM - distant metastases, DFS-disease free survival, OS-overall survival, HIR-high-intermediate risk, UPSC-uterine papillary serous carcinoma, CC - clear cell

${ }^{\ddagger}$ Carboplatin and paclitaxel, ${ }^{\dagger}$ Some variation exists in the definition of high-risk groups in the referenced studies and within the present series 
Guidelines state that treatment options for women with high-grade, stage I tumors with deep myometrial invasion, and adverse risk factors include observation alone, radiation therapy alone, or radiation therapy with chemotherapy. Radiation therapy offers an additional range of choices: pelvic EBRT alone, VBT alone, or pelvic EBRT with VBT [34]. Treatment guidelines for early-stage papillary serous and clear cell carcinoma are similarly varied.

Data are now emerging for early outcomes following VBT with or without chemotherapy in well defined, HIR and high-risk subgroups of women with stage I and II endometrial cancer. Specifically, the rates of vaginal and pelvic failure in these studies ranged 1.2-3.2\% and $3-9 \%$, respectively, after 2-5 years of follow up (Table 6) $[9,20,24,25,35-37]$. The most notable study of VBT in women with HIR disease comes from the experimental arm of the second PORTEC trial (PORTEC-2) [9]. The definition of HIR disease in PORTEC-2 and GOG 99 differ, however, there is considerable overlap in these patient populations. At five years, VBT provided excellent vaginal control (98.2\%), with pelvic recurrence (3.8\%) and distant metastases $(8.3 \%)$ being the predominant patterns of failure [9]. Additionally, a second study from Mayo Clinic reported outcomes from 103 high-risk women with stage I papillary serous and clear cell carcinoma treated with adjuvant VBT with or without chemotherapy. The 5-year estimates of vaginal recurrence (3\%) and loco-regional recurrence $(7 \%)$ were similarly low [20]. Data from PORTEC-2 has provided high-level evidence for the use of VBT without pelvic EBRT in patients with HIR disease; however, similar data for patients with high-risk, early stage disease (cervical stromal invasion and type II histology) is limited to retrospective, single-institution studies like the present series $[20,24,25,37]$. Therefore, results should be interpreted with caution as pelvic EBRT may provide an important benefit in loco-regional control for early stage patients at high-risk for recurrence.

We report rates of vaginal $(1.9 \%)$, pelvic $(2.4 \%)$, and distant $(9.1 \%)$ recurrences that are consistent with many contemporary series using VBT in subgroups of HIR and high-risk, early stage endometrial cancer (Table 6). At only three years, however, the relapse rates in our study cohort already approach the five-year outcomes from PORTEC-2 in which vaginal, pelvic, and distant relapse rates were $1.8 \%, 3.8 \%$, and $8.3 \%$, respectively, in HIR patients treated with adjuvant VBT without chemotherapy. This can be attributed to the inclusion of high-risk patients in our study cohort and, in fact, all loco-regional recurrences described in this study occurred in high-risk patients. The inclusion of HIR patients dilutes the overall recurrence rates. In the present series, three-year rates of vaginal relapse were $3.2 \%$ and $0 \%$ among high-risk and HIR patients, respectively. Similarly, three-year rates of pelvic relapse were $3.8 \%$ and $0 \%$ among high-risk and HIR patients, respectively. While the difference between these recurrence rates and those of HIR patients was not statistically significant, the data were not powered to detect such a difference. The higher rates of loco-regional recurrences in high-risk patients argue that pelvic EBRT is warranted for this subgroup. The anticipated treatment benefit afforded by EBRT may justify the risk of added toxicity. Currently, the standard of care for high-risk patients remains pelvic EBRT with consideration of chemotherapy until future larger studies can provide definite conclusions regarding the role of VBT with chemotherapy [38].

This study does not address the potential importance of chemotherapy in this patient population and the results neither argue for or against the routine use of combined chemotherapy and radiotherapy. In the present series, the subgroup of patients who received chemotherapy cannot be effectively compared with the subgroup that did not receive chemotherapy due to inherent biases that were present while recommending adjuvant therapies for patients treated at our institution. There are, however, data that support a role for chemotherapy in this patient population, including from the Japanese Gynecologic Oncology Group $[10,12,39]$. In a randomized trial of pelvic EBRT versus cisplatin-based chemotherapy in patients with stage IC-IIIC disease with deeper than $50 \%$ myometrial invasion, chemotherapy improved progression free survival and OS compared to pelvic EBRT in a high- to intermediate-risk subgroup [10]. Included in this subgroup were patients with stage II disease, and patients over 70 years old with grade 3 tumors or stage IC disease - a population similar to the present series. Whether chemotherapy should be included as a standard portion of adjuvant therapy in this patient population remains a topic of active investigation in GOG 0249 and other trials $[14,28]$.

Important limitations of this study include the lack of a second cohort for comparison and inherent biases associated with retrospective study. Additionally, the findings in this study might be heavily influenced by the small number of observed relapse events and could change substantially with longer follow up. The number of patients in this study is too low for any firm conclusions, and standard treatment for high-risk patients should continue to involve pelvic EBRT with chemotherapy as we await additional prospective data. The results of contemporary clinical trials will be forthcoming as to whether pelvic EBRT may be omitted in women with high-risk, early stage endometrial cancer [14].

\section{Conclusions}

The contemporary clinical trial GOG 0249 has defined practical criteria that identify a population of patients with high-risk, early stage endometrial cancer. Adjuvant pelvic EBRT remains a standard of care in this patient population and data regarding VBT and chemotherapy are limited. This regimen is well tolerated by patients with mostly mild, grade 1-2 acute toxicities. Distant metastases remain prevalent in patients receiving VBT alone, suggesting a role for chemotherapy. Early outcomes following adjuvant VBT with or without chemotherapy demonstrate high rates of vaginal control, pelvic control, and survival among the HIR subgroup, while early loco-regional relapses in the high-risk subgroup argue that pelvic EBRT with chemotherapy should remain a standard of care. Additional data with long-term follow up are needed to determine whether pelvic EBRT can be omitted in women with high-risk, early stage disease. 


\section{Acknowledgements}

The authors would like to thank Lilya Babinsky for her assistance with the endometrial cancer database search. The National Cancer Institute (NCI) should be acknowledged for providing our institution with a Cancer Center Support Grant (P30 CA56036) which promotes clinical research within our institution.

\section{Disclosure}

Authors report no conflict of interest.

\section{References}

1. Keys HM, Roberts JA, Brunetto VL et al. A phase III trial of surgery with or without adjunctive external pelvic radiation therapy in intermediate risk endometrial adenocarcinoma: a Gynecologic Oncology Group study. Gynecol Oncol 2004; 92: 744-751.

2. Creutzberg CL, Nout RA, Lybeert ML et al. Fifteen-year radiotherapy outcomes of the randomized PORTEC-1 trial for endometrial cancer. Int J Radiat Oncol Biol Phys 2011; 81: e631-e638.

3. ASTEC/EN.5 Study Group, Blake P, Swart AM, Orton J et al. Adjuvant external beam radiotherapy in the treatment of endometrial cancer (MRC ASTEC and NCIC CTG EN.5 randomized trials): pooled trial results, systematic review, and meta-analysis. Lancet 2009; 373: 137-146.

4. Aalders J, Abeler V, Kolstad P et al. Postoperative external irradiation and prognostic parameters in stage I endometrial carcinoma: clinical and histopathologic study of 540 patients. Obstet Gynecol 1980; 56: 419-427.

5. Nout RA, van de Poll-Franse LV, Lybeert ML et al. Longterm outcome and quality of life in patients with endometrial carcinoma treated with our without pelvic radiotherapy in the post operative radiation therapy in endometrial carcinoma 1 (PORTEC-1) trial. J Clin Oncol 2011; 29: 1692-1700.

6. Creutzberg CL, van Putten WL, Koper PC et al. The morbidity of treatment for patients with stage I endometrial cancer: results from a randomized trial. Int J Radiat Oncol Biol Phys 2001; 51: 1246-1255

7. Kellas-Ślęczka S, Wojcieszek P, Białas B. Adjuvant vaginal brachytherapy as part of a management in early endometrial cancer. J Contemp Brachyther 2012; 4: 247-252.

8. Creutzberg CL, van Putten WL, Koper PC et al. Survival after relapse in patients with endometrial cancer: results from a randomized trial. Gynecol Oncol 2003; 89: 201-209.

9. Nout RA, Smit VT, Putter H et al. Vaginal brachytherapy versus pelvic external beam radiotherapy for patients with endometrial cancer of high-intermediate risk (PORTEC-2): an open-label, non-inferiority, randomized trial. Lancet 2010; 375: 816-823.

10. Susumu N, Sagae S, Udagawa Y et al. Randomized phase III trial of pelvic radiotherapy versus cisplatin-based combined chemotherapy in patients with intermediate- and high-risk endometrial cancer: A Japanese Gynecologic Oncology Group study. Gynecol Oncol 2008; 108: 226-233.

11. Greven K, Winter K, Underhill $\mathrm{K}$ et al. Final analysis of RTOG 9708: Adjuvant postoperative irradiation combined with cisplatin/paclitaxel chemotherapy following surgery for patients with high-risk endometrial cancer. Gynecol Oncol 2006; 103: 155-159.

12. Jutzi L, Hoskins P, Lim P et al. The importance of adjuvant chemotherapy and pelvic radiotherapy in high-risk early stage endometrial carcinoma. Gynecol Oncol 2013; 131: 581585.
13. Ayeni TA, Bakkum-Gamez JN, Mariani A et al. Comparative outcomes assessment of uterine grade 3 endometrioid, serous, and clear cell carcinomas. Gynecol Oncol 2013; 129: 478-485.

14. Gynecologic Oncology Group (GOG). Pelvic radiation therapy or vaginal implant radiation therapy, paclitaxel, and carboplatin in treating patients with high-risk stage I or II endometrial cancer. In: ClinicalTrials.gov [Internet]. Bethesda (MD): National Library of Medicine (US). 2000 [cited 2013 Nov 8]. Available from: http://clinicaltrials.gov/show/ NCT00807768. NLM Identifier: NCT00807768.

15. Alektiar KM, Makker V, Abu-Rustum NR et al. Concurrent carboplatin/paclitaxel and intravaginal radiation in surgical stage I-II serous endometrial cancer. Gynecol Oncol 2009; 112: 142-145.

16. Tchabo NE, McCloskey S, Mashtare TL et al. Treatment of early-stage uterine papillary serous carcinoma at Roswell Park Cancer Institute, 1992-2006. Gynecol Oncol 2009; 155: 249-256.

17. Viswanathan AN, Macklin EA, Berkowitz R et al. The importance of chemotherapy and radiation in uterine papillary serous carcinoma. Gynecol Oncol 2011; 112: 542-547.

18. Growdon WB, Rauh-Hain JJ, Cordon A et al. Prognostic determinants in patients with stage I uterine papillary serous carcinoma: a 15-year multi-institutional review. Int J Gynecol Cancer 2012; 22: 417-424.

19. Kim A, Schreiber D, Rineer J et al. Impact of adjuvant external-beam radiation therapy in early-stage uterine papillary serous and clear cell carcinoma. Int J Radiat Oncol Biol Phys 2011; 81: e639-e644.

20. Barney BB, Petersen IA, Mariani A et al. The role of vaginal brachytherapy in the treatment of surgical stage I papillary serous or clear cell endometrial cancer. Int J Radiat Oncol Biol Phys 2013; 85: 109-115.

21. Yechieli R, Rasool N, Robbins JR et al. Adjuvant radiation therapy for patients with type II endometrial carcinoma: Impact on tumor recurrence and survival. Int J Gynecol Cancer 2013; 23: 763-768.

22. Huh WK, Powell M, Leath CA et al. Uterine papillary serous carcinoma: Comparisons of outcomes in surgical stage I patients with and without adjuvant therapy. Gynecol Oncol 2003; 91: 470-475.

23. Sutton G, Axelrod JH, Bundy BN et al. Adjuvant whole abdominal irradiation in clinical stage I and II papillary serous or clear cell carcinoma of the endometrium: A phase II study of the Gynecologic Oncology Group. Gynecol Oncol 2006; 100: 349-354.

24. Kiess AP, Damast S, Makker V et al. Five-year outcomes of adjuvant carboplatin/paclitaxel chemotherapy and intravaginal radiation for stage I-II papillary serous endometrial cancer. Gynecol Oncol 2012; 127: 321-325.

25. Townamchai K, Berkowitz R, Bhagwat $M$ et al. Vaginal brachytherapy for early stage uterine papillary serous and clear cell endometrial cancer. Gynecol Oncol 2013; 129: 18-21.

26. Creasman WT, Kohler MF, Odicino F et al. Prognosis of papillary serous, clear cell, and grade3 stage I carcinoma of the endometrium. Gynecol Oncol 2004; 95: 593-596.

27. Crisano FD, Robboy SJ, Dodge RK et al. The outcome of stage I-II clinically and surgically staged papillary serous and clear cell endometrial cancers when compared with endometrioid carcinoma. Gynecol Oncol 2000; 77: 55-65.

28. Leiden University Medical Center. Randomized trial of radiation therapy with or without chemotherapy for endometrial cancer (PORTEC-3). In: ClinicalTrials.gov [Internet]. Bethesda (MD): National Library of Medicine (US). 2000 [cited 2013 Nov 8]. Available from: http://clinicaltrials.gov/ show/NCT00411138. NLM Identifier: NCT00411138. 
29. Van der Steen-Banasik E. Primary brachytherapy as a radical treatment for endometrial carcinoma. J Contemp Brachytherapy 2014; 6: 106-112.

30. McMeekin DS, Filiaci VL, Aghajanian C et al. A randomized phase III trial of pelvic radiation therapy (PXRT) versus vaginal cuff brachytherapy followed by paclitaxel/carboplatin chemotherapy $(\mathrm{VCB} / \mathrm{C})$ in patients with high risk (HR), early stage endometrial cancer (EC): a Gynecologic Oncology Group trial. Proceedings of the $45^{\text {th }}$ Annual Meeting on Women's Cancer, Society of Gynecologic Oncology, Tampa, FL (2014, March 22).

31. Ko EM, Funk MJ, Clark LH et al. Did GOG99 and PORTEC1 change clinical practice in the United States? Gynecol Oncol 2013; 129: 12-17.

32. Albuquerque K, Shah K, Potkul R. Vaginal dehiscence after intracavitary brachytherapy for endometrial cancer. J Contemp Brachytherapy 2012; 4: 111-112.

33. Donnelly ED, Rakhra S, Helenowski I et al. Dosimetry and toxicity outcomes in postoperative high-dose-rate intracavitary brachytherapy for endometrial cancer. J Contemp Brachytherapy 2012; 4: 135-140.

34. National Comprehensive Cancer Network (NCCN) Clinical Practice Guidelines in Oncology. Uterine neoplasms, version 3.2012. National Comprehensive Cancer Network; 2012.

35. Atahan IL, Ozyar E, Yildiz F et al. Vaginal high dose rate brachytherapy alone in patients with intermediate- to highrisk stage I endometrial carcinoma after radical surgery. Int J Gynecol Cancer 2008; 18: 1294-1299.

36. McCloskey SA, Tchabo NE, Malhotra et al. Adjuvant vaginal brachytherapy alone for high risk localized endometrial cancer as defined by the three major randomized trials of adjuvant pelvic radiation. Gynecol Oncol 2010; 116: 404-407.

37. Desai NB, Kiess AP, Kollmeier MA et al. Patterns of relapse in stage I-II uterine papillary serous carcinoma treated with adjuvant intravaginal radiation with or without chemotherapy. Gynecol Oncol 2013 (In Press). http://dx.doi.org/10.1016/j. ygyno.2013.09.019.

38. Klopp A, Smith BD, Alektiar K et al. The role of postoperative radiation therapy for endometrial cancer: Executive Summary of the American Society for Radiation Oncology evidence-based guideline. Pract Radiat Oncol 2014; 4: 137-144.

39. Randall M, Filiaci V, Muss H et al. Randomized phase III trial of WART versus doxorubicin and cisplatin chemotherapy in advanced endometrial carcinoma: A GOG study. J Clin Oncol 2006; 24: 36-44. 